ONE HUNDRED AND SIXTY-EIGHTH SCIENTIFIC MEETING

COLLEGE HALL, LONDON HOSPITAL IMEDICAL COLLEGE, ASHFIELD STREET, LONDON, E 1

3 UL̈IUBEK 1964

\title{
AVAILABILITY OF MINERALS IN FOODS OF PLANT ORIGIN
}

\author{
Chairman: Professor G. N. Jenkins, MSc, PhD, Sutherland Dental School, \\ University of Newcastle upon Tyne
}

\section{Mineral availability and techniques for its measurement}

\section{By A. Thompson, Department of Agricultural Biochemistry, University of Newcastle upon Tyne}

In the study of mineral metabolism it is generally recognized that the total content of an element in a particular dietary source has little significance unless it is qualified by a factor indicating the biological 'utilization' of the element. However, there appears to be less agreement as to what constitutes 'utilization' and how it should be expressed. This has resulted in a number of terms, e.g. percentage availability (true and apparent), percentage utilization, percentage digestibility (true and apparent), percentage absorption, percentage retention, and such like, many of which have been used as synonyms by some authors though being given precise definition by others.

Apart from any confusion in terminology there appear to be two different concepts of availability, though these are by no means mutually exclusive. In animal nutrition, particularly that concerned with the ruminant, more emphasis appears to be placed upon the degree to which the element can be extracted from different dietary sources. 'This implies that 'availability' is a characteristic of a particular source. Thus, many comparisons of feeds and feed supplements have been made using animals of the same age, with identical body stores and total intakes of the element; the resulting differences in utilization, often very considerable, are valid in this context.

In other work, particularly studies with man, it is clear that the term 'availability' is being used to characterize the metabolic state of the body rather than the dietary source. Studies in which comparisons are made between subjects of different ages or with varied body status of the element, all receiving identical amounts of the same dietary source, clearly reflect this view of 'availability'.

The difference in degree of emphasis upon these two concepts is understandable in view of the very considerable mineral demands of high-producing farm livestock. When an animal, such as a dairy cow, may secrete amounts of calcium or phosphorus of $20-30 \mathrm{~g}$ or more per day, it is probable that the degree of extraction of these elements from the dietary source is the limiting factor.

In the subsequent discussion of 'availability' reference will be made to the simplified flow scheme which, along with the relevant definitions of nomenclature, 


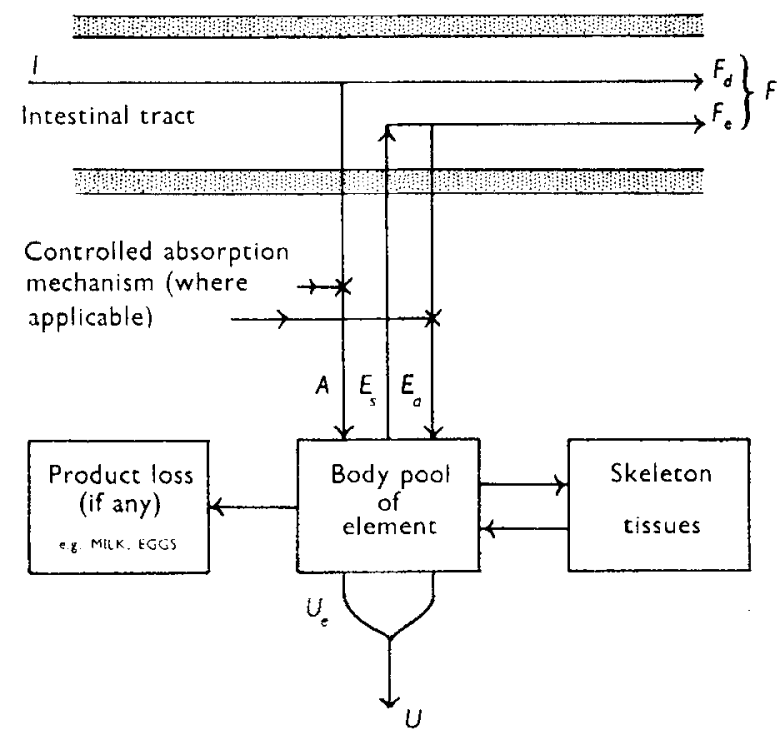

Fig. I. Scheme for mineral absorption and excretion connected with the intestinal tract.

$I$, intake of dietary element; $F$, total excretion of element in faeces; $U$, total excretion of element in urine; $U_{e}$, excretion of element in urine at zero net retention; $F_{d}$, faecal excretion of unabsorbed dietary element; $F_{\varepsilon}$, net excretion of element of body origin into intestinal tract; $E_{s}$, total endogenous element secreted into intestinal tract; $E_{a}$, endogenous element reabsorbed from intestinal tract; $A$, dietary element absorbed from intestinal tract.

is shown in Fig. I. This scheme, with minor modifications, may be considered to apply to most of the biologically important elements. It is important to note that the scheme should not be taken as suggesting: (a) that absorption and secretion occur at single points along the intestinal tract, or that the two processes occur in the order shown; (b) that mixing will not take place in the tract between endogenous and dietary element (only for purposes of clarity are they shown separately); (c) that the endogenous excretion is necessarily composed entirely of elements in digestive secretions.

Table I shows four commonly used expressions of utilization based upon the flow scheme; all four have been referred to by different workers as 'percentage availability'

Table I. Some commonly employed methods of expressing percentage dietary mineral intake 'available' to the body

\begin{tabular}{|c|c|c|c|c|c|c|}
\hline & & Equation & & & $\begin{array}{l}\text { Equation expr } \\
\text { in terms of } \\
\text { retention }(I\end{array}$ & $\begin{array}{l}\text { ressed } \\
\text { net } \\
R)\end{array}$ \\
\hline $\begin{array}{l}\text { Term used in } \\
\text { the present text }\end{array}$ & & $\times \frac{1}{100}$ & & & $\times \frac{I}{100}$ & \\
\hline $\begin{array}{l}\% \text { Apparent digestibility } \\
\% \text { True digestibility } \\
\% \text { Net retention }(R)\end{array}$ & $\begin{array}{l}= \\
= \\
=\end{array}$ & $\begin{array}{l}I-F \\
I-\left(F-F_{e}\right) \\
I-(F+U)\end{array}$ & $\begin{array}{l}(1) \\
(2) \\
(3)\end{array}$ & $\begin{array}{l}= \\
=\end{array}$ & $\begin{array}{l}R+U \\
R+U+F_{e}\end{array}$ & $\begin{array}{l}(5) \\
(6)\end{array}$ \\
\hline
\end{tabular}

The symbols are explained in Fig. 1. 
as well as by other terms. The terms used in the present review, namely, percentage apparent digestibility, percentage true digestibility, percentage net retention and percentage availability have little virtue other than in being distinctive and in having the same essential meaning as when used for organic food constituents.

Equation 2 is merely a refinement of equation $I$ in that the faecal endogenous excretion is measured and credited to the dietary source. Similarly equation 4 is a refinement of equation 3 by crediting the dietary source with the total endogenous excretion $\left(\mathrm{F}_{\mathrm{e}}+\mathrm{U}_{\mathrm{e}}\right)$. The really important difference in these expressions is that equations $I$ and 2 credit urinary excretion to the dietary source on the grounds that it represents the element that has been absorbed from the intestinal tract, whereas equations 3 and 4 consider the fate of the element within the animal and debit urinary excretion against the dietary source.

If these equations are re-expressed in terms of the net retention (Table I) it may be seen that equation 6 for percentage true digestibility and equation 7 for percentage availability differ only in whether the maintenance or total urinary excretion is included. It is reasonable to assume that in the region of negative to zero retentions $\mathrm{U}$ will approximate to $\mathrm{U}_{\mathrm{e}}$ and therefore only when high dietary intakes result in high urinary excretion will the two terms materially differ. The magnitude of such differences will further depend upon the partition of the excreted element between urine and faeces in the particular animal species under study. With calcium in the ruminant, the urinary excretion may be virtually ignored compared to that in the faeces, but this cannot be assumed with other elements and other species (Mitchell, 1964).

As percentage net retention and percentage apparent digestibility take no account of endogenous losses, dietary mineral intakes below maintenance commonly result in negative values for these two expressions (Hansard, Comar \& Plumlee, 1954; Thompson, Hansard \& Bell, I 959); these are clearly unacceptable as expressions of dietary 'utilization'. Percentage true digestibility and percentage availability which do allow for endogenous losses clearly have limiting values of zero.

\section{Methods commonly employed to determine 'availability'}

Chemical balance studies. While the apparent digestibility (equation $\mathrm{I}$ ) is the least satisfactory expression, the simplicity of the method, which requires only a knowledge of the intake and total faecal excretion, has commended itself to many workers. Rook \& Campling ( 1962 ) have pointed out that most information on magnesium utilization in ruminants is calculated on this basis.

These authors point out, however, that when the apparent digestibility of a dietary source is low, as with magnesium in many ruminant feeds, then the errors of any conventional balance study become large. Using the alternative expression (equation 5), Rook \& Campling calculated percentage apparent digestibility by determining only the urinary excretion. As the animals concerned were considered to have zero net retentions of magnesium this procedure was considered justifiable.

The inclusion of the urinary as well as the faecal excretions allows the calculation of the percentage net retention (equation 3), which is the basis for many reported 
utilization data, particularly for calcium and phosphorus (Mitchell, 1964). Though this expression is valuable in estimating the minimum amount of the element of use to the animal it is of limited use for mature animals or for animals being given maintenance levels of mineral, when values approaching zero are obtained. Consequently the percentage net retention has been most successfully used as an assay method to compare the relative utilizations of different dietary sources at intake levels which promote retention in young growing animals. In some instances (Armstrong \& Thomas, 1952) the net retention has been determined from the analysis of food and excreta, but in many it has been determined by whole-body analysis of animals after a known intake compared with that of similar animals at the beginning of the feeding period (Fincke \& Sherman, I935; Armstrong \& Thomas, 1952). The latter workers carried out both carcass analysis and a very carefully conducted balance experiment to determine the net retention of calcium by rats from different dietary sources and found excellent agreement between the two methods. Consolazio, Matoush, Nelson, Hackler \& Preston (1962) have, however, pointed out that losses of calcium in sweat may introduce errors into balance experiments with man. This may be an even more important factor with other elements.

Before percentage true digestibility or percentage availability can be calculated, the endogenous losses, particularly the endogenous faecal loss, must be determined. Much of the controversy associated with availability measurements has centred on these fractions. Added importance is given by the fact that the total endogenous excretion is equated to the maintenance requirement of the body. Mitchell (1964) and Hansard, Comar \& Plumlee (1954) both accept this, but with very different assumptions and result.

Estimates of faecal and urinary endogenous losses, particularly of calcium and phosphorus, using diets free of these elements have been made on various animal species, but for most availability measurements these fractions have been estimated indirectly. Using regressions of retention of the element (or total output) on its intake, the total endogenous output, equal to the constant in the regression, has been calculated, e.g. for calcium and phosphorus in man (quoted by Mitchell, I964), for calcium in poultry (Tyler \& Willcox, 1942), for magnesium in calves (Blaxter \& Rook, 1954). Estimates of mineral utilization as given by the regression coefficient will clearly be availability as defined in equation 4 . The use by Field (1962) of a regression of faecal magnesium excretion on intake, which gives a constant equal to the faecal endogenous loss, allows the calculation of true digestibility as defined in equation 3 . Though not actually determining endogenous values as such, Steggerda \& Mitchell (1939) determined the availability of calcium in human diets by giving the test materials at two levels of intake, one very low and the other at about maintenance, and calculating the change in calcium retention relative to the change in calcium intake. This procedure, in common with those using regressions, assumes that the endogenous excretions are constant from zero intake to at least maintenance levels.

Methods involving the use of radioactive isotopes. The introduction of techniques with radioactive isotopes into mineral metabolism studies represented a major 
advance, for despite the controversy which exists regarding the validity of their use in certain situations, they have made possible a more dynamic interpretation of mineral metabolism (Aubert, Bronner \& Richelle, I963) in contrast to the static picture suggested by earlier work.

Radioisotopic procedures have been widely used for the determination of true digestibilities of dietary minerals, particularly of calcium and phosphorus (Visek, Monroe, Swanson \& Comar, I953; Hansard \& Plumlee 1954; Hansard, Lyke \& Crowder, I961; Thompson et al, I959; Kleiber, Smith, Ralston \& Black, 195I; and others). In a number of the above-mentioned studies values for calcium and phosphorus were obtained by the simultaneous use of ${ }^{45} \mathrm{Ca}$ and ${ }^{22} \mathrm{P}$ in the same animal. Field (1959) and Macdonald, Care \& Nolan (1959) have used ${ }^{28} \mathrm{Mg}$ in the determination of the true digestibility of magnesium.

In general, two methods employing radioisotopes have been used to determine the true digestibility of a dietary mineral source, namely the isotope dilution procedure and the comparative balance.

Briefly, the isotope dilution procedure consists of labelling the element in the plasma by the intravenous injection of multiple (Visek et al. 1953) or single (Hansard, Comar \& Plumlee, 1952) doses of the radioisotope and the subsequent measurement, at equilibrium, of the extent of the dilution of the total element in the faeces by element of endogenous origin. The fraction of endogenous loss in the faecal excretion is measured by the ratio of faecal $\left(S A_{F}\right)$ to plasma $\left(S A_{P}\right)$ specific activities.

The isotope dilution method assumes: (a) That the plasma is uniformly labelled and in equilibrium with the tissues. From a consideration of published disappearance curves (Hansard, Comar \& Davis, I 954) this would seem to be a justifiable assumption if adequate time is allowed before plasma and faeces samples are taken for radioassay, e.g. 3-4 days with calcium and phosphorus (Thompson et al. 1959). (b) the endogenous excretion into the intestinal tract has the same specific activity as the plasma. This would appear to be a justifiable procedure, though Field (I96I) has doubted this for magnesium. Some workers, particularly when using small animals, have preferred to use the specific activity of the urine rather than that of the plasma (Kjerulf-Jensen, I 94I).

The comparative balance procedure estimates true digestibility directly, using radioisotope balance data derived from pairs of animals, one dosed intravenously and the other orally with a single tracer dose of radioactivity. 'The true digestibility is calculated from the expression

$$
\% \text { true digestibility }=\frac{\mathrm{I} 00-\% \text { radioisotope in faeces }}{\mathrm{I}-B}(\% \text { of oral dose }) \text {, }
$$

where $B$ equals the fraction of the intravenously administered radioisotope excreted in the faeces.

The comparative balance does not require the calculation of the faecal endogenous loss, although it can be derived from the data if a normal calcium balance has been simultaneously carried out. In addition, as one of the pair of animals has been intravenously dosed, this animal can be used independently to calculate the true digestibility of the element by the isotope dilution method. Agreement between the two 
procedures has been found, by most workers, to be good. Aubert et al. (1963) have proposed a procedure in which the orally and intravenously administered radioisotope is given to the same animal in the form of two different isotopes of the same element. Individuality between pairs of animals is thereby eliminated.

The main assumption in the comparative balance procedure is that the dietary source becomes fully labelled by the orally administered radioisotope, for the true digestibility as calculated above applies strictly to the administered radioactive element. In a considerable number of experiments of this type inorganic or readily exchangeable sources of dietary element were used in semi-purified diets and here the assumption would seem valid. However, Tillman \& Brethour (r958) have questioned this assumption in their study of the digestibility of phosphorus in diets containing phytate, and Field (I96r) has similarly questioned the assumption in the labelling of herbage magnesium.

The above assumption is avoided when the dietary source is pre-labelled as in the work by Ammerman, Arrington, McCall, Feaster, Combs \& Davis, (1963) in which the uniformity of labelling was confirmed.

A very considerable volume of data has now been published on the availability of minerals in dietary sources, together with the relevant estimates of faecal endogenous excretion. Consideration of this material, which is largely concerned with calcium and phosphorus utilization in cattle, sheep, pigs and rats, leads to some generalized observations on endogenous faecal excretion.

(a) The endogenous faecal mineral excretions, estimated by radioisotopic procedures, for animals receiving about maintenance intakes of the element are higher than those estimated using diets free of the element in question, or by regression analysis.

(b) Over the major part of an animal's life-span, the endogenous faecal excretion (as $\mathrm{mg} / \mathrm{kg}$ ) remains reasonably constant. Very young and very old animals, however, show considerably lower and higher excretions respectively.

(c) Previous mineral status appears to affect endogenous faecal mineral loss in that low and high body status results in higher and lower endogenous losses respectively.

Such estimates of faecal endogenous excretions have been criticized by a number of workers (Mitchell, I964; Field, I96I; Moore \& Tyler, I955) largely on the assumption that exchange reactions invalidate the procedures. It must, however, be admitted that the evidence for or against the existence of exchange reactions is very meagre. Exchange between radioisotope entering the intestinal tract in endogenous secretions and the exogenous element already present does not in itself invalidate the use of isotopic procedures to estimate the fraction of the element in faeces originally of body origin. Only when the exchange takes place between the endogenous isotope and an exchangeable yet unavailable form of exogenous element would the estimate be invalidated. Clearly, if such exchanges take place, they are more probable with dietary sources of very low availability.

Data of Hansard \& Plumlee (I 954) and of Kjerulf-Jensen (I 94I) are often quoted as evidence against the validity of radioisotopic procedures for estimating faecal 
endogenous loss. Both experiments would appear to show considerable increases in endogenous faecal excretion with increasing intakes. It should be noted that in both, high or very high levels were given to animals which had previously been subjected to high intake of the element for a considerable period of time. It may well be that these results reflect body status more than dietary intake. Even so, there appears to be little reason why endogenous faecal excretion should be regarded as necessarily constant. The amount of element of endogenous origin appearing in the faeces is itself the net result of secretion and reabsorption rates $\left(E_{s}-E_{a}\right)$ and must obviously be subject to the absorptive state of the intestinal tract. There is increasing evidence that for certain elements, at least, absorption is not merely a diffusive process but is the result of a controlled intestinal transport mechanism (Cramer \& Dueck, I 962). Clearly, endogenous faecal excretion will be subject to all the physiological factors which control the mechanism.

Biological assay procedures. The problems associated with any type of balance study have led many workers to consider methods which will give at least a comparative measure of the degree of utilization of minerals in dietary sources. Precision is greatest when the animal species used in the assay is in fact that whose diet is being ultimately considered, and when the comparison is made against a standard source whose availability is known.

The simple criterion of live-weight gain has been used by Long, Tillman, Nelson, Davis \& Gallup (I956) to assess phosphorus supplements for cattle by adding them to a low-phosphorus diet.

Calcium and phosphorus retention has frequently been assessed by measuring the incremental retention in a selected bone caused by a known amount of dietary element (Ammerman, Norton, Scott \& Nesbit, 1960). This technique can only be used with young growing animals. Lengemann (1959) and Patrick \& Bacon (1957) have used the ${ }^{45} \mathrm{Ca}$ content of rat tibias or femurs to assess utilization of dietary sources of calcium labelled by an oral dose of radioisotope. Apart from the ease of assay, this modification makes possible the use of older animals. Clearly, the same assumptions on completeness of labelling apply equally here as in the comparative balance.

Very extensive use has been made of the blood level as a measure of mineral utilization, particularly of iron and magnesium. The utilization of iron of a number of herbage species was measured by Thompson \& Raven (1959) by means of the relative rates of haemoglobin regeneration in rats rendered anaemic by prior feeding on an iron-deficient diet. The use of radioisotopic ${ }^{59} \mathrm{Fe}$ has lessened the need to work with anaemic subjects, and a number of studies is reported in which vegetables, eggs, and meat labelled with ${ }^{59} \mathrm{Fe}$ have been grown or prepared and the iron utilization measured as ${ }^{59} \mathrm{Fe}$ uptake by the blood in normal subjects.

In-vitro assay procedures. For the routine assessment of mineral utilization the advantages of a method not requiring the use of animals are obvious. However, few such methods have been reported, and even these do not find general acceptance. The determination of 'available' iron by means of the dipyridyl reagent which reacts with ionic ferrous iron has been shown to be unsound (Miller \& Louis, I945). 
Anderson, Cheng \& Burroughs (1956) have devised a rapid in vitro method of evaluating phosphorus supplements for ruminants by measuring the decomposition of cellulose in an artificial rumen when the supplements were the sole source of phosphorus for the micro-organisms. The values obtained were in reasonable agreement with those found by animal experiment.

This brief survey of some of the many methods employed to determine the utilization of minerals from dietary sources serves to illustrate the wide interest in this aspect of mineral metabolism. Such interest is justified for, when the availability of a food mineral is shown to be of a very low order even for animals which are in a semi-deficiency state, the implications for the nutritionist are considerable and the scope for research unlimited.

\section{REFERENCES}

Ammerman, C. B., Arrington, L. R., McCall, J. T., Feaster, J. P., Combs, G. E. \& Davis, G. K. (1963). f. Anim. Sci. 22, 890 .

Ammerman, C. B., Norton, H. W., Scott, H. M. \& Nesbit, A. H. (1960). Poult. Sci. 39, 245.

Anderson, R., Cheng, E. \& Burroughs, W. (1956). J. Anim. Sci. 15, 489.

Armstrong, R. H. \& Thomas, B. (1952). F. agric. Sci. 42, 454.

Aubert, J. P., Bronner, F. \& Richelle, L. J. ( 1963$)$. F. clin. Invest. 42, 885.

Blaxter, K. L. \& Rook, J. A. F. (1954). F. comp. Path. 64, I76.

Consolazio, C. F., Matoush, L. O., Nelson, R. A., Hackler, L. R. \& Preston, E. E. (1962). F. Nutr. 78, 78.

Cramer, C. F. \& Dueck, J. (I962). Amer. F. Physiol. 202, 16r.

Field, A. C. (1959). Nature, Lond., 183, $98_{3}$.

Field, A. C. (1961). Brit. F. Nutr. 15, 349.

Field, A. C. (1962). Brit. F. Nutr. 16, 99.

Fincke, M. L. \& Sherman, H. C. (1935). F. biol. Chem. 110, $42 \mathrm{I}$.

Hansard, S. L., Comar, C. L. \& Davis, G. K. (1954). Amer. F. Physiol. 177, 383.

Hansard, S. L., Comar, C. L. \& Plumlee, M. P. (1952). Y. Anim. Sci. II, 524.

Hansard, S. L., Comar, C. L. \& Plumlee, M. P. (1954). F. Anim. Sci. 13, 25.

Hansard, S. L., Lyke, W. A. \& Crowder, H. M. (r961). F. Anim. Sci. 20, 292.

Hansard, S. L. \& Plumlee, M. P. (1954). F. Nutr. 54, 17.

Kjerulf-Jensen, K. (194I). Acta physiol. scand. 3, suppl. 9 and Io, p.r.

Kleiber, M., Smith, A. H., Ralston, N. P. \& Black, A. I. (195I). F. Nutr. 45, 253.

Lengemann, F. W. (1959). Y. Nutr. 69, 23.

Long, T. A., Tillman, A. D., Nelson, A. B., Davis, B. \& Gallup, W. D. (1956). F. Anim. Sci. 15, I 1 2. Macdonald, D. C., Care, A. D. \& Nolan, B. (1959). Nature, Lond., 184, 736.

Miller, C. D. \& Louis, L. (1945). F. Nutr. 30, 485 .

Mitchell, H. H. (1964). Comparative Nutrition of Man and Domestic Animals. New York and London: Academic Press Inc.

Moore, J. H. \& Tyler, C. (1955). Brit. F. Nutr. 9, 63.

Patrick, H. \& Bacon, J. A. (1957). F. biol. Chem. 228, 569.

Rook, J. A. F. \& Campling, R. C. (1962). F. agric. Sci. 59, 225.

Steggerda, F. R. \& Mitchell, H. H. (1939). F. Nutr. 17, 253.

Thompson, A., Hansard, S. L. \& Bell, M. C. (1959). F. Anim. Sci. 18, 187.

Thompson, A. \& Raven, A. M. (1959). F. agric. Sci. 52, I 77.

Tillman, A. D. \& Brethour, J. R. (1958). F. Anim. Sci. 17, 104.

Tyler, C. \& Willcox, J. S. (I942). F. agric. Sci. 32, 62.

Visek, W. J., Monroe, R. A., Swanson, E. W. \& Comar, C. L. (1953). F. Nutr. 5o, 23. 